\title{
Recent advances on heterocyclic compounds with antiviral properties
}

\author{
Aramita De ${ }^{1}$, Subhankar Sarkar ${ }^{1}$, Adinath Majee ${ }^{1 *}$ \\ ${ }^{1}$ Department of Chemistry, Visva-Bharati, Santiniketan, \\ West Bengal 731235, India; e-mail: adinath.majee@visva-bharati.ac.in
}

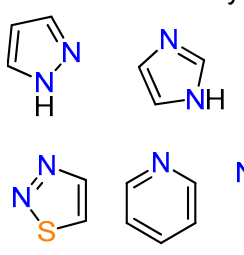

Heterocyclic compounds with antiviral properties

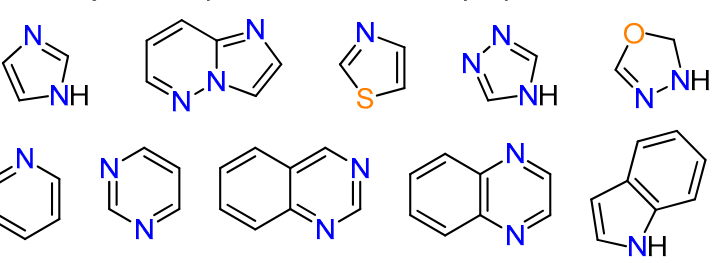

In recent years several important viral infections have emerged and antiviral chemotherapeutic agents are not sufficiently effective in clinic, leading to serious human diseases and mortality. Therefore, novel antiviral candidates are urgently desirable, which undoubtedly is essential for the therapy of various fatal and debilitating viral infections. Heterocyclic compounds are obtaining importance in the field of medicinal chemistry because of the broad spectrum of their physiological activities. Among N- and S-containing heterocycles, indole, imidazole, thiazole, pyridine, and quinaxoline derivatives are especially attractive. The present review highlights antiviral behavior of these heterocyclic compounds.

Keywords: antiviral activity, biological activity, cytotoxicity, virus.

Viral infections cause diseases in humans, animals, and even plants. Plant viruses are frequently spread from plant to plant through insects, whereas some viruses of animals, including humans, ${ }^{1}$ are spread by exposure to infected body fluids. Viruses such as influenza, norovirus, rotavirus, dengue, human immunodeficiency virus (HIV) are frequently transmitted by cough, sneeze, contaminationinfected food, blood-sucking insects, and through sexual contacts. Within the last five years two major outbreaks of Ebola virus have happened in Africa, ${ }^{2}$ Zika virus has spread throughout the Americas, ${ }^{3}$ and recently a novel coronavirus $(2019-\mathrm{nCoV})$ has been diagnosed in people. ${ }^{4}$ Antibiotics have no effects on viruses, ${ }^{5}$ whereas antiviral drugs have been recognized to treat life-threatening infections. Vaccines that produce life-long immunity can preclude some viral infections. ${ }^{6}$

Nowadays, heterocyclic compounds are hot research area due to their wide range of applications in the fields of medicinal chemistry, materials chemistry, photochemistry, agrochemicals etc. ${ }^{7-10}$ In 2010, US retail sales described that $80 \%$ of drug molecules contain heterocyclic fragment. ${ }^{11}$ In this review, we will mainly focus on heterocyclic derivatives comprising indole, isoindole, pyrazole, imidazole, indazole, imidazopyridine, thiazole, triazole, oxadiazole, thiadiazole, pyridine, pyrimidine, quinazoline, quinoxaline and on their antiviral properties toward various viruses including herpes simplex virus 1, 2 (HSV-1, HSV-2), influenza A virus (IAV), hepatitis A, B, C viruses (HAV, $\mathrm{HBV}$, and $\mathrm{HCV}$ ), respiratory syncytial virus (RSV), bovine viral diarrhea virus (BVDV), rotavirus A (RVA), human adenovirus type 7 (HAdV7), Coxsackieviruses B4, B5 (CV-B4, CV-B5), Junin virus (JUNV), Epstein-Barr virus (EBV), tobacco mosaic virus (TMV), flavivirus, feline coronavirus (FCoV), feline herpes virus (FHV), vesicular stomatitis virus (VSV), human immunodeficiency virus (HIV), human cytomegalovirus (HCV), varicella zoster virus $(\mathrm{VZV})$, vaccinia virus, tick-borne encephalitis virus (TBEV) that have been explored during the past two decades (Table 1).

\section{Indole and isoindole}

Indole scaffold has been found in many important synthetic drug molecules and paved a faithful way to develop effective targets. Privileged structures bind to multiple receptors with high affinity, thus aiding the development of novel biologically active compounds. Indole is a potent basic pharmacophore presented in a wide variety of antiviral agents which inhibit HSV-1. AbdelGawad et al. reported that indole fragment fused with 1,2,4-triazolo[3,4-b]-1,3,4-thiadiazine and 1,3-thiazole 
Table 1. Heterocycle-containing compounds and their antiviral applications

\begin{tabular}{|c|c|c|c|}
\hline $\begin{array}{l}\text { Heterocyclic } \\
\text { fragment }\end{array}$ & Name of the compound & Virus type & $\begin{array}{l}\text { Refe- } \\
\text { rence }\end{array}$ \\
\hline \multirow[t]{3}{*}{ Indole } & 5-(1H-Indol-3-yl)-1-phenyl- $N$-(4,5,6,7-tetrachloro-1,3-dioxoisoindolin-2-yl)- $1 H$-pyrazole-3-carboxamide (1a) & HSV-1 & 12 \\
\hline & 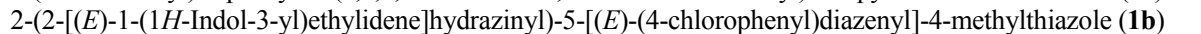 & HSV-1 & 12 \\
\hline & 2-Hydroxypyrazino[1,2-a]indole-1,3(2H,4H)-dione (1 ca) & IAV, $\mathrm{HCV}$ & 13 \\
\hline Isoindole & $\begin{array}{l}\text { (S)-9b-(4-Chlorophenyl)-1-nicotinoyl-1,2,3,9b-tetrahydro-5H-imidazo[1',2':1,2]pyrrolo[3,4-c]pyridin- } \\
\text { 5-one (BTA9881) (2a) }\end{array}$ & RSV & 14 \\
\hline \multirow[t]{2}{*}{ Pyrazole } & 6-Chloro-9-fluoro-3-phenyl-3H-benzo $[b]$ pyrazolo $[3,4-h][1,6]$ naphthyridine (3ad) & HSV-1 & 15 \\
\hline & 1-(4-Chlorophenyl)-3-methyl-5-phenyl-5,6-dihydropyrrolo[3,4-c]pyrazol-4(1H)-one (3b) & BVDV & 16 \\
\hline \multirow[t]{3}{*}{ Imidazole } & $N, N, 1$-Trimethyl-2-(thiazol-4-yl)-1 $H$-benzo[ $[d$ imidazole-5-carboxamide (4a) & & \\
\hline & 2-(2-Methyl-5-nitro-1H-benzo[d]imidazol-1-yl)-3-(5-methylfuran-2-yl)-1-phenylprop-2-en-1-one (4b) & HBV & 17 \\
\hline & (Z)-2-(2-Methyl-5-nitro-1 $H$-benzo[ $d]$ imidazol-1-yl)-1-phenyl-3-(thiophen-2-yl)prop-2-en-1-one (4c) & RVA, HAdV7 & 18 \\
\hline \multirow{2}{*}{$\begin{array}{l}\text { Imidazo- } \\
\text { pyridine }\end{array}$} & 3-[(1,1'-Biphenyl)-3-yl]-2-(4-fluorophenyl)-6-(phenylsulfanyl)imidazo[1,2-a]pyridine (5a) & $\mathrm{HCV}, \mathrm{BVDV}$ & 19 \\
\hline & 3'-[2-(2-Methoxyphenyl)-6-(thiophen-3-yl)imidazo[1,2-b]pyridazin-3-yl]-1,1'-biphenyl-2-ol (5b) & & \\
\hline \multirow[t]{5}{*}{ Indazole } & & CV-B4, RVA, & 20 \\
\hline & 2-[7-(4-Chlorobenzylidene)-3-(4-chlorophenyl)-5-phenyl-4,5,6,7-tetrahydro-2 $\mathrm{H}$-indazol-2-yl]- & & \\
\hline & 7-methylbenzo $[d]$ thiazole $(\mathbf{6 a b})$ & & \\
\hline & 2-[7-(2,6-Dimethoxybenzylidene)-3-(2,6-dimethoxyphenyl)-5-phenyl-4,5,6,7-tetrahydro-2 $\mathrm{H}$-indazol- & & \\
\hline & 2-yl]-7-methylbenzo[ $d]$ thiazole $(\mathbf{6 b})$ & & \\
\hline \multirow[t]{8}{*}{ Thiazole } & [2-(4-Bromobenzoyl)imidazo[2,1-b]thiazol-5-yl][(3a $R, 5 S, 6 R, 6 \mathrm{a} R)$-6-methoxy- & JUNV & 21 \\
\hline & 2,2-dimethyltetrahydrofuro[2,3- $d][1,3]$ dioxol-5-yl]methanone (7aa) & & \\
\hline & 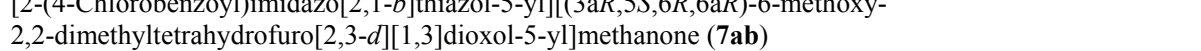 & & \\
\hline & $(2 E, 5 E)-5$-(5-Acetyl-3-phenyl-1,3,4-thiadiazol-2(3H)-ylidene)-2-\{[4-(1,5-dimethyl-3-oxo-2-phenyl- & $\mathrm{HCV}$ & 22 \\
\hline & 2,3-dihydro-1 $H$-pyrazol-4-yl)thiazol-2-yl]imino \}-3-phenylthiazolidin-4-one (7b) & & \\
\hline & $(6 R, 7 S)-7-(4-E t h o x y p h e n y 1)-2-o x o-3,5,6,7$-tetrahydro- $2 H$-thiopyrano[2,3-d]thiazole-6-carbaldehyde (7ca) & & \\
\hline & 4-((6R,7S)-6-Formyl-2-oxo-3,5,6,7-tetrahydro-2H-thiopyrano[2,3-d] thiazol-7-yl)phenyl benzoate (7cb) & EBV & 23 \\
\hline & $N$-(4-Nitrobenzyl)benzo $[d]$ thiazol-6-amine (7d) & $\mathrm{HCV}, \mathrm{IAV}$ & 24 \\
\hline \multirow[t]{2}{*}{ Triazole } & $(2 R, 3 R, 4 S, 5 R)$-2-(3-Ethynyl-1H-1,2,4-triazol-1-yl)-5-(hydroxymethyl)tetrahydrofuran-3,4-diol (ETAR) (8a) & Flavivirus & 25 \\
\hline & 3 - $\{5$-[4-(Trifluoromethyl)phenyl]-4H-1,2,4-triazol-3-yl $\}-1 H$-indole $(\mathbf{8 b})$ & TMV & 26 \\
\hline \multirow[t]{3}{*}{ Oxadiazole } & 5-(4-Amino-3-ethyl-2-thioxo-2,3-dihydrothiazol-5-yl)-1,3,4-oxadiazole-2(3H)-thione (9aa) & FCoV, FHV, HSV-1 & 27 \\
\hline & 5-(4-Amino-3-phenyl-2-thioxo-2,3-dihydrothiazol-5-yl)-1,3,4-oxadiazole-2(3H)-thione (9ab) & and HSV-2 & \\
\hline & 2-[5-(2-Phenylhydrazinylidene)-4,5-dihydro-1,3,4-oxadiazol-2-yl]acetonitrile (9b) & $\begin{array}{l}\text { Vaccinia virus, } \\
\text { HSV, CV-B4, VSV }\end{array}$ & \\
\hline \multirow[t]{4}{*}{ Thiadiazole } & 2-Methylsulfanyl-5-(4-methyl-1,2,3-thiadiazol-5-yl)-1,3,4-oxadiazole (10aa) & TMV & 28 \\
\hline & 2-Ethylsulfanyl-5-(4-methyl-1,2,3-thiadiazol-5-yl)-1,3,4-oxadiazole (10ab) & & \\
\hline & 2-[(4-Chlorobenzyl)sulfanyl]-5-(4-methyl-1,2,3-thiadiazol-5-yl)-1,3,4-oxadiazole (10ac) & & \\
\hline & 2-(Methylsulfonyl)-5-(4-methyl-1,2,3-thiadiazol-5-yl)-1,3,4-oxadiazole (10b) & & \\
\hline \multirow[t]{6}{*}{ Pyridine } & 3-Benzyl-3-ethyl-6-methyl-3H-[1,2] oxathiolo[4,3-b]pyridine 1,1-dioxide (11aa) & HIV, HCMV, & 29 \\
\hline & Methyl 3-benzyl-3-ethyl-3H-[1,2] oxathiolo[4,3-b]pyridine-6-carboxylate 1,1-dioxide (11ab) & VZV, etc. & 30 \\
\hline & 3-Benzyl-3-ethyl- $N$-methyl-3H-[1,2]oxathiolo[4,3-b]pyridine-6-carboxamide 1,1-dioxide (11ac) & & \\
\hline & 2-(3-Bromophenyl)-4-\{4-[(6-chloropyridin-3-yl)methoxy]phenyl\}-2,3-dihydrobenzo[b][1,4]thiazepine (11b) & & \\
\hline & 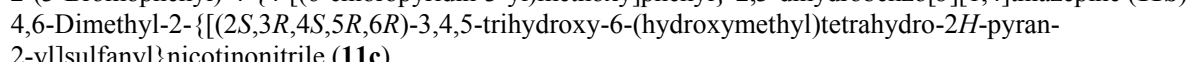 & TMV & 31 \\
\hline & & CV-B4 and HSV-1 & 30 \\
\hline \multirow[t]{4}{*}{ Pyrimidine } & 5-[5-(sec-Butylsulfanyl)-1,3,4-thiadiazol-2-yl]-2-methylpyrimidin-4-amine (12a) & TMV & 32 \\
\hline & $N-\{4-[N-(4-\{[4-(4-C y a n o-2,6-d i m e t h y l p h e n o x y) t h i e n o[3,2-d]$ pyrimidin- & & \\
\hline & 2-yl]amino cyclohexyl)sulfamoyl]phenyl $\}$ acetamide (12ba) & HIV & 33 \\
\hline & 4-Cyano- $N$-(4- $\{[4-(4-c y a n o-2,6-d i m e t h y l p h e n o x y)$ thieno[3,2-d]pyrimidin- & & \\
\hline Quinazoline & $\mathrm{N}$-[2-(Adamantan-1-yl)ethyl]-2-tert-butyl-5 6,7.8-tetrahydroquinazolin-4-amine 1-oxide (13a). & TBEV & 34 \\
\hline \multirow[t]{6}{*}{ Quinaxoline } & Ethyl 4-\{[(2,3-dimethoxyquinoxalin-6-yl)methyl]sulfanyl $\}$ benzoate (14aa) & CV-B5 & 35 \\
\hline & 4-\{[(2,3-Dimethoxyquinoxalin-6-yl)methyl] sulfanyl $\}$ benzoic acid (14ab) & & \\
\hline & Ethyl 6-\{[(2,3-dimethoxyquinoxalin-6-yl)methyl]sulfanyl $\}$ nicotinate (14ac) & & \\
\hline & Ethyl 2-(6,7-dimethyl-3-oxo-3,4-dihydroquinoxalin-2-yl)acetate $(\mathbf{1 4 b})$ & & \\
\hline & 6,7-Dimethyl-3-\{[4-(pyridin-2-yl)-4H-1,2,4-triazol-3-yl]methyl $\}$ quinoxalin-2 $(1 H)$-one (14c) & $\mathrm{HCV}$ & 36 \\
\hline & $(1 E, 3 Z, 4 E)-1$-[4-(4-Chlorobenzyl)phenyl]-5-(pyridin-2-yl)penta-1,4-dien-3-one $O$-quinoxalin-2-yl oxime (14d) & TMV & 37 \\
\hline
\end{tabular}




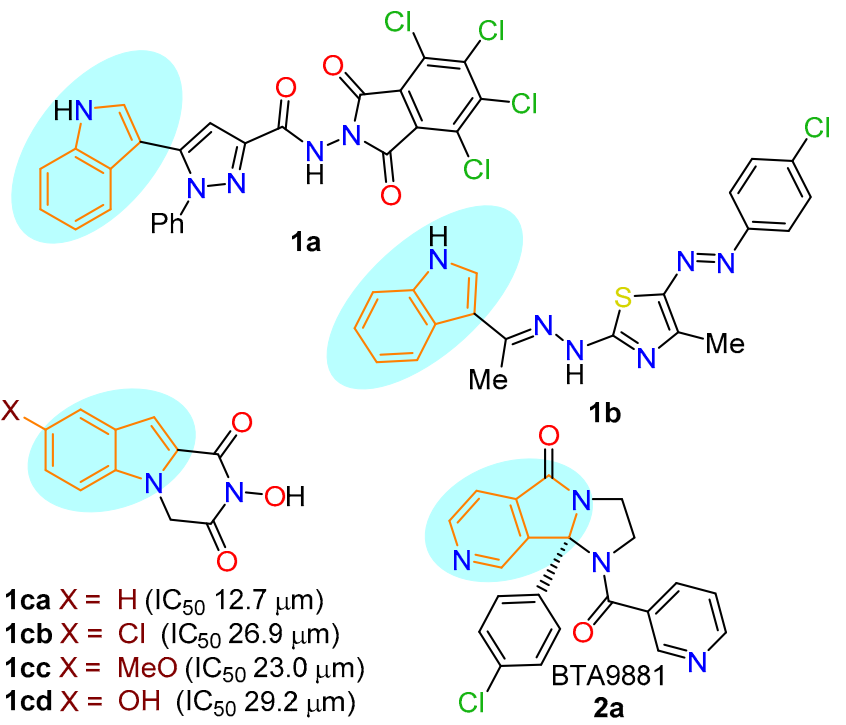

Figure 1. Derivatives of indole and isoindole.

derivatives displayed potent antiviral activity against HSV-1 grown on Vero cells. A variety of indole derivatives were synthesized and tested with the hope to get better antiviral agents. Among the tested derivatives, compounds $\mathbf{1 a}, \mathbf{b}$ (Fig. 1) showed the highest activity and reduced the number of viral plaques of HSV-1 with respect to aphidicolin as positive control. ${ }^{12}$

On the other hand, a series of flutimide analogs, specifically novel lipophilic 1,2-annulated indole diketopiperazines were rationally developed. Various substituents such as $\mathrm{OH}, \mathrm{MeO}, \mathrm{Cl}$, and $\mathrm{F}$ were introduced into the core structure. The obtained analogs were evaluated for their inhibitory effect on IAV and HCV RNA replication in the subgenomic replicon assay. Pyrazino[1,2-a]indole1,3(2H,4H)-diones 1ca-cd (Fig. 1) following mild and experimentally convenient protocol, offer a promising motif for further construction of new analogs with improved antiviral properties through appropriate substitution in diketopiperazine or indole cycles. Cytotoxicity of compounds was determined toward Huh 5-2 replicon cells and HEK293T cells. $^{13}$

Isoindole ring is well-used heterocyclic unit in organic chemistry and is naturally occurring in some alkaloids. Isoindole moiety fused with different heterocycles displayed potent antiviral activity against RSV which is a major cause of respiratory tract infections in infants, children, and adults. The antiviral activity was found to inherent in a single enantiomeric series, and compound $\mathbf{2 a}$, known also as BTA9881, was identified as a candidate for preclinical trials (Fig. 1). ${ }^{14}$

\section{Pyrazole, imidazole, imidazopyridine, indazole}

Pyrazole is a ubiquitous motif in biologically active compounds and therefore represents an interesting template for medicinal chemistry. Pyrazole derivatives are the subject of many investigations due to their extensive potential biological activities. Bernardino et al. synthesized and evaluated different pyrazolonaphthyridine derivatives

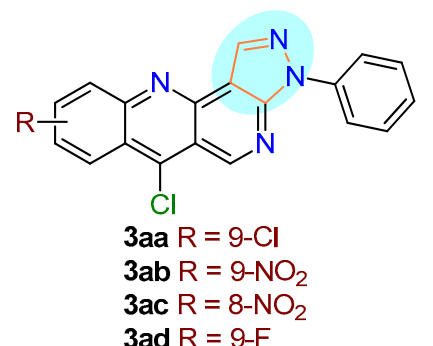<smiles>Cc1nn(-c2ccc(Cl)cc2)c2c1C(=O)N(c1ccccc1)C2</smiles><smiles>Cc1ccc(/C=C(\C(=O)c2ccccc2)N(c2ccc([N+](=O)[O-])cc2)C(C)C)o1</smiles>

$\left(\mathrm{IC}_{50} 1.1 \mu \mathrm{M}\right)$

4b<smiles>CC(=N)N(C(C)=CC(=O)c1ccccc1)c1ccc([N+](=O)[O-])cc1</smiles><smiles>Fc1ccc(-c2nc3ccc(Sc4ccccc4)cn3c2-c2cccc(-c3ccccc3)c2)cc1</smiles>

$\left(\mathrm{EC}_{50} 2.0 \mu \mathrm{M}\right.$ against BVDV)

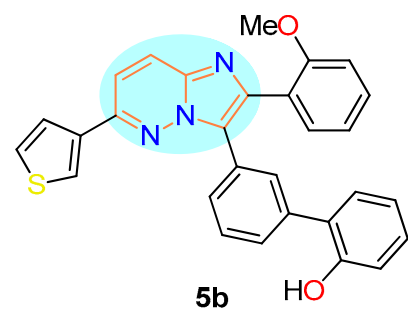

$\left(\mathrm{EC}_{50} 1.4 \mu \mathrm{M}\right.$ against BVDV $\mathrm{EC}_{50} 4.8 \mu \mathrm{M}$ against $\mathrm{HCV}$ )<smiles>COc1cccc(OC)c1/C=C1\CC(c2ccccc2)Cc2c1nn(-c1nc3cccc(C)c3s1)c2-c1c(OC)cccc1OC</smiles>

Figure 2. Derivatives of pyrazole, imidazole, indazole, and imidazopyridine.

with potential activity against HSV-1. In general, $3 H$-benzo[b]pyrazolo[3,4- $h]-1,6$-naphthyridines were more effective inhibitors than the corresponding $3 H$-pyrido[2,3- $b]$ pyrazolo[3,4- $h]$ 1,6-naphthyridines. Compounds 3aa-ad (Fig. 2) exhibited the highest antiHSV-1 activity among obtained derivatives. They were tested as inhibitors of HSV replication in Vero cells (obtained from the American type culture collection) . Thus, compound 3ad prevented the effect of HSV-1 on Vero cells up to $91 \%$ at $50 \mu \mathrm{M}$ concentration and exhibited low cytotoxicity $\left(\mathrm{CC}_{50} 600 \mu \mathrm{M}\right){ }^{15}$

Similarly, a series of novel pyrazole-fused derivatives had been successfully synthesized through a one-pot two- 
step procedure. Their antiviral activity was investigated by Han and coworkers. Thus, compound 3b (Fig. 2) showed the highest antiviral activity against BVDV in MadinDarby bovine kidney (MDBK) cells and lower cytotoxicity using the MTT method than ribavirin as positive control. ${ }^{16}$

Luo et al. synthesized a series of novel thiazolylbenzimidazole derivatives and evaluated their antiviral activity against HBV and cytotoxicity on the HepG2.2.15 cell line. Among the derivatives, compound 4a (Fig. 2) showed good antiviral activity and high selectivity. ${ }^{17}$

A series of novel 5-nitro- $1 \mathrm{H}$-benzimidazole derivatives substituted at $\mathrm{N}-1$ position by heterocyclic systems were synthesized, and their antiviral activity against RVA and HAdV7 was evaluated. Compounds $\mathbf{4 b , c}$ (Fig. 2) were the most promising with high antiviral activity in Hep-2 and MA104 cell lines (obtained from VACSERA, Egypt) previously cultured in 96-well multiwell plates (GreinerBio One, Germany) to estimate nontoxic doses of the tested samples. ${ }^{18}$

Imidazopyridine is one of the important fused heterocycles and is recognized as a "drug prejudice" scaffold due to the wide range of its application in medicinal chemistry. A series of novel biphenyl derivatives of imidazo[1,2-a]pyridine and imidazo[1,2- $b]$ pyridazine were synthesized by Enguehard-Gueiffier et al. using known hit compound Ttou 84 to optimize the inhibitory properties on the replication of the BVDV and HCV by introducing various substituents at different sites of the hit. Thus, compound 5a (Fig. 2) was proved to be the most selective inhibitor of BVDV replication. Pyridazine derivative 5b (Fig. 2) showed antiviral activity in the HCV replicon system. ${ }^{19}$

Tetrahydroindazoles and their derivatives have attracted attention due to their exclusive pharmacological applications. Indazole derivatives were synthesized by condensation reaction of 4-phenylcyclohexanone with various aldehydes and were employed in antiviral activity tests against CV-B4, HAdV7, and RVA using the plaque assay method. Indazole derivative 6aa exhibited moderate activity against both CV-B4 and RVA and possesses promising activity against HAdV7. Noteworthy, that indazoles $\mathbf{6 a b}$ and $\mathbf{6 b}$ revealed higher activity against HAdV7 and also revealed promising activity against rotavirus Wa strain (Fig. 2). ${ }^{20}$

\section{Thiazole}

Thiazole is an effective nucleus for wide range of applications as pharmaceutical agents. It was first described by Hantzsch and Weber in $1887 .^{38}$ Thiazoles occur naturally and are isolated from microbial and marine sources. The scaffold is present in more than 18 FDA-approved drugs and as a part of more than 70 experimental drugs.

A series of C-3,5-disubstituted imidazo[2,1-b]thiazoles with a carbohydrate moiety and halobenzoyl group were synthesized by Barradas et al. Cytotoxicity was evaluated in Vero cells by MTT method, and antiviral activity was assayed using JUNV strain IV4454 as the model system. The desired products $7 \mathbf{a a}, \mathbf{a b}$ were obtained by a convergent synthetic pathway from available 6-bromo-6-deoxy1,2-O-isopropylidene-3-O-methyl- $\alpha-\mathrm{D}$-xylo-hexofuranos-

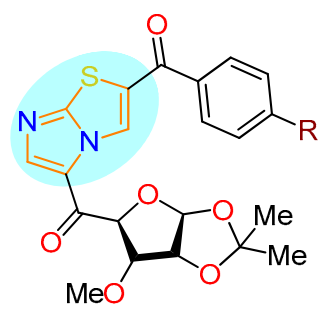

7aa $\mathrm{R}=\mathrm{Br}\left(\mathrm{EC}_{50} 1.1 \mu \mathrm{M}\right)$

7ab $\mathrm{R}=\mathrm{Cl}\left(\mathrm{EC}_{50} 0.8 \mu \mathrm{M}\right)$

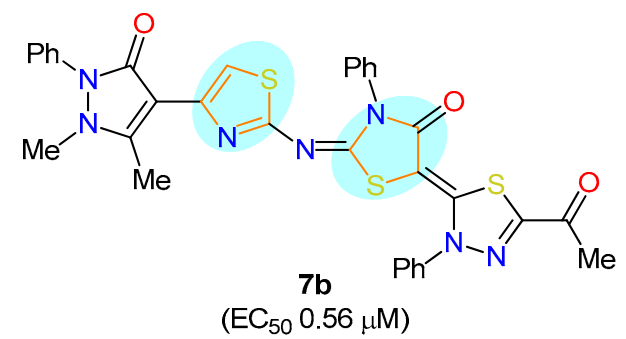

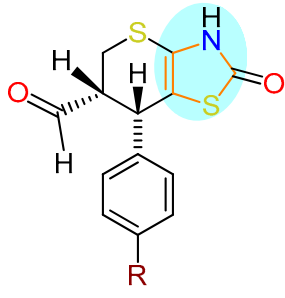

7ca $\mathrm{R}=\mathrm{MeO}\left(\mathrm{EC}_{50} 0.07 \mu \mathrm{M}\right)$

$7 \mathrm{cb} \mathrm{R}=\mathrm{BzO}\left(\mathrm{EC}_{50} 12.6 \mu \mathrm{M}\right)$

Figure 3. Derivatives of thiazole.

5-ulose. Interestingly, that antiviral activity of the analyzed compounds decreased drastically when the Me group of the carbohydrate residue was replaced by the more polar Ac group. The most active compounds 7aa, 7ab (Fig. 3) showed higher antiviral activity against JUNV in Vero cells than the reference substance ribavirin. ${ }^{21}$

The synthesis of the compounds based on bisthiazole motif connected to pyrazole or thiadiazole scaffold with imine linker were reported by Dawood et al. in order to fight $\mathrm{HCV}$ virus. The in vitro antiviral screening of the test compound was achieved in USA. Product $\mathbf{7 b}$ showed promising activity against HCV virus strain (CON-1, Genotype-1b) and was subjected to further screening (Fig. 3). ${ }^{22}$

Lozynskyi et al. revealed a convenient protocol for the synthesis of a series of novel thiopyrano[2,3- $d$ ] thiazole6-carbaldehydes via regio- and diastereoselective heteroDiels-Alder reaction of 5-arylidene-4-thioxo-2-thiazolidinone by the $[4+2]$ cyclization with acrolein. The synthesized compounds were evaluated for antiviral activity according to the antimicrobial acquisition and coordinating facility (AACF) screening program. Compounds $\mathbf{7} \mathbf{c a}, \mathbf{c b}$ were found to be the most active. Thus, compound $7 \mathbf{c a}$ showed the best antiviral activity against EBV in Daudi cell cultures and compound $\mathbf{7} \mathbf{c b}$ was the most active against HCV (Fig. 3). ${ }^{23}$

IAV is extremely disposed to cause periodic epidemics and pandemics in the world through evolution by point mutations or swapping of gene segments, correspondingly. $\mathrm{Hu}$ et al. demonstrated antiviral effect of $N$-(4-nitrophenyl- 
methyl)benzothiazol-6-amine (7d), known as N30, against IAV, including oseltamivir- and amantadine-resistant strains. The authors have excluded the target of neuraminidase or hemagglutinin and found that N30's antiviral mechanism may involve the inhibition of guanine nucleotide synthesis by inhibiting the activity of inosine-5'-monophosphate dehydrogenase type II (Fig. 3). ${ }^{24}$

\section{Triazole, oxadiazole, thiadiazole}

1,2,4-Triazole is an important five-membered heterocycle found in many molecules with significant biological activities. $\quad 1-\beta$-D-Ribofuranosyl-3-ethynyl[1,2,4]triazole (ETAR) (8a) is a promising broad-spectrum antiviral drug with substantially higher efficacy than ribavirin against flaviviruses via inhibition of the enzyme inosine-5'-monophosphate dehydrogenase (IMPDH) and has comparable in vitro toxicity (Fig. 4). ${ }^{25}$

Zhao et al. designed and synthesized a series of nortopsentin analogs containing 1,2,4-triazole system, which showed good antiviral activities against TMV in vivo (Fig. 4). Compound $\mathbf{8 b}$ with higher antiviral activity than nortopsentin D and ribavirin emerged as a new antiviral lead compound. ${ }^{26}$

The synthesized 1,3,4-oxadiazole-containing thiazole derivatives 9aa,ab (Fig. 4) were evaluated as cytotoxic and antiviral agents against FCoV, FHV, HSV-1, and HSV-2 which might be also due to the presence of $4-\mathrm{NH}_{2}$ group in thiazole moiety. Compounds 9aa,ab were obtained from 1,3,4-oxadiazole derivative 2-(5-thioxo-4,5-dihydro-1,3,4oxadiazol-2-yl)acetonitrile in presence of ethyl isothiocyanate and phenyl isothiocyanate, respectively. Noteworthy, that compound $9 \mathbf{b}$ among the analogs was the most effective against vaccinia virus, HSV, CV-B4, and VSV. ${ }^{27}$

Modification of substituents of 1,2,3-thiadiazole has little impact on versatility in biological activity. Thus, for example, in 2010, two independent groups presented a series of 4-methyl-1,2,3-thiadiazole-containing 1,2,4-triazoles $^{39}$ and 4-methyl-1,2,3-thiadiazole-5-carboxylates, ${ }^{40}$ which possessed good antiviral activity. Similarly, Xu et al. few years later generated a number of 1,2,3-thiadiazole and
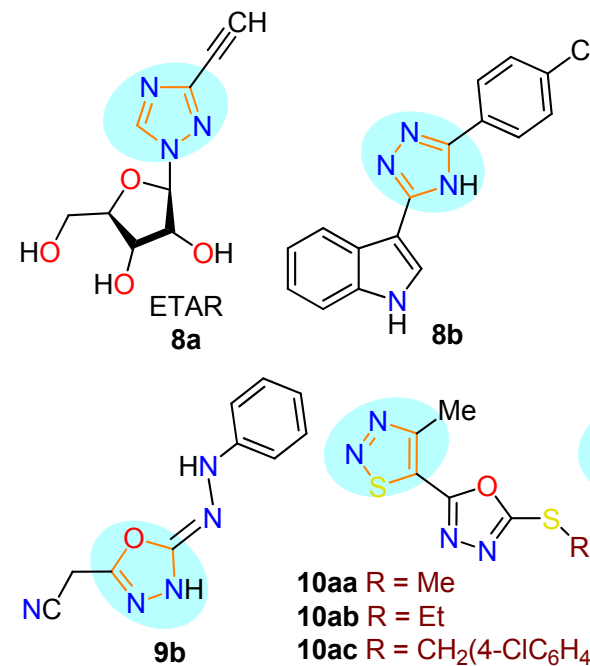

10aa $\mathrm{R}=\mathrm{Me}$

10ab $R=E t$

10ac $\mathrm{R}=\mathrm{CH}_{2}\left(4-\mathrm{ClC}_{6} \mathrm{H}_{4}\right)$

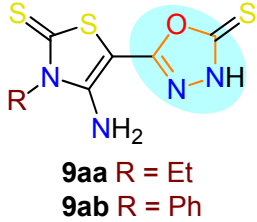

9aa $R=E t$
9ab $R=P h$

Figure 4. Derivatives of triazole, oxadiazole, and thiadiazole. 1,3,4-oxadiazole derivatives containing thioether and sulfone groups 10aa-ac and 10b which showed potent antiviral activities against $\mathrm{TMV}{ }^{28}$

\section{Pyridine, pyrimidine}

From the biological interest, the synthesized fused bicyclic systems with various functional groups allow to form new interactions with cellular or viral targets. De Castro et al. described $\beta$-amino- $\gamma$-sultone as useful intermediate for the synthesis of previously virtually unknown $3 H$-[1,2]oxathiolo[4,3-b]pyridine 1,1-dioxide bicyclic heterocyclic systems (Fig. 5) and evaluated these novel structures against HIV, HCMV, VZV, and a broad variety of other DNA/RNA viruses. Authors were pleased to found that compounds 11aa-ac inhibited HIV-1-induced cytopathicity. ${ }^{29}$

A series of novel 1,5-benzothiazepine derivatives containing pyridine moiety were synthesized and screened for their antiviral activity against TMV in vivo. The corresponding target compounds with different substituents exhibited curative activity against TMV compared to that of Ningnanmycin. Thus, compound 11b was identified as an excellent lead compound with antiviral activity against TMV as well as the most promising candidate for the agricultural use. This research indicated that target compounds may function as potential lead structures for the discovery of new antiviral agents. ${ }^{31}$

Thioglycosides, where the anomeric carbon of the sugar motif is linked to the proper heterocycle through a thioether bond, were recognized to be of biological interest. Elgemeie et al. worked on the synthesis, antiviral and cytotoxic activities of a number of heterocyclic thioglycosides such as pyridine thioglycosides, pyrimidine thioglycosides, imidazole thioglycosides, pyrazole thioglycosides, triazole thioglycosides, oxadiazole thioglycosides, thiophene thioglycosides, quinoline thioglycosides, thienopyrazole thioglycosides, and pyrazolopyrimidine thioglycosides. Recently, this research team has incorporated the phosphoramidate functionality to pyridine- and pyrimidine-based thioglycosides as sofosbuvir thio analogs. The compounds were prepared by coupling mercaptoderivatized heterocyclic bases with the appropriate $\alpha$-bromo- $O$-acetylated sugars and followed by the hydrolysis of the acetate esters under basic conditions that were consequently conjugated with the phosphoramidating reagent to afford the desired thioglycoside protides. The compounds were estimated for their antiviral activities against different viral cell lines: HAdV7, HAV, CV-B4, and HSV-1. Only compounds 11c,d showed notable antiviral activity against CV-B4, reflected from the $\mathrm{CC}_{50}$ values of 17 and $20 \mu \mathrm{g} / 100 \mu \mathrm{l}$ and $\mathrm{IC}_{50}$ values of 4.5 and $6.0 \mu \mathrm{g} / 100 \mu \mathrm{l}$, respectively. The same two compounds elicited remarkable activities toward HSV-1, represented by $\mathrm{CC}_{50}$ values of 17 and $16 \mu \mathrm{g} / 100 \mu \mathrm{l}$ and $\mathrm{IC}_{50}$ values of 6.3 and $6.6 \mu \mathrm{g} / 100 \mu \mathrm{l}$, respectively. Only compound 11d showed a remarkable activity against $\mathrm{HCV} .{ }^{30}$

2-Substituted 2-methylpyrimidin-5-yl-1,3,4-thiadiazole derivatives (Fig. 5) were synthesized by $\mathrm{Wu}$ et al. and evaluated for antiviral activity against TMV in vivo. 


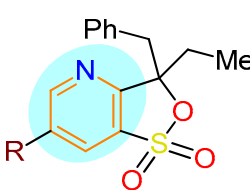

11aa $\mathrm{R}=\mathrm{Me}$

11 ac $\mathrm{R}=\mathrm{CONHMe}$

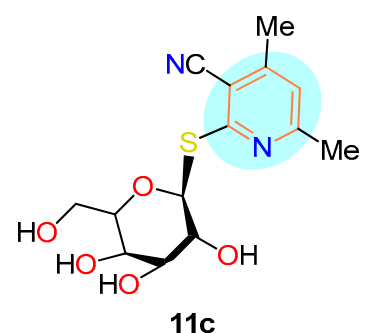

$11 \mathrm{c}$

$\left(\mathrm{IC}_{50} 4.5 \mu \mathrm{M}\right.$ against $\mathrm{CV}-\mathrm{B} 4$, $\mathrm{IC}_{50} 6.3 \mu \mathrm{M}$ against $\mathrm{HSV}-1$ )

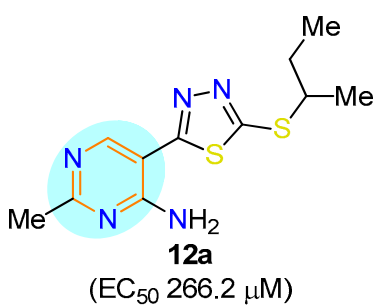

$\left(\mathrm{EC}_{50} 266.2 \mu \mathrm{M}\right)$
$11 \mathrm{ab} \mathrm{R}=\mathrm{CO}_{2} \mathrm{Me}$
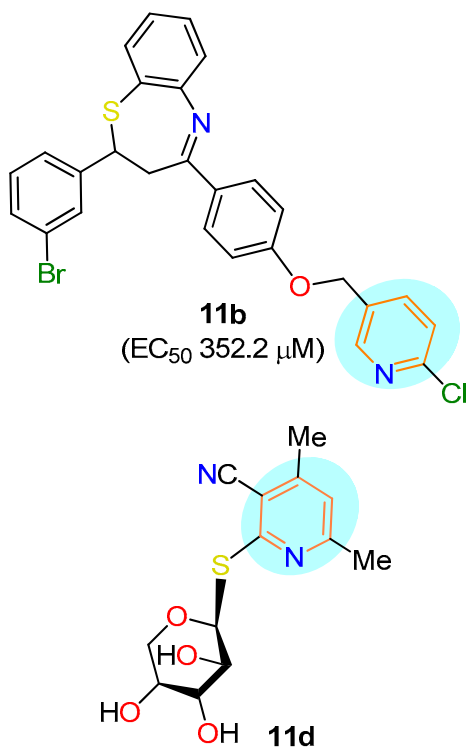

$\left(\mathrm{IC}_{50} 6.0 \mu \mathrm{M}\right.$ against CV-B4, $\mathrm{IC}_{50} 6.6 \mu \mathrm{M}$ against $\mathrm{HSV}-1$ )

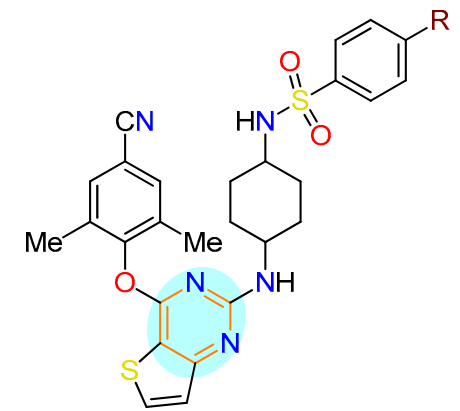

12ba R = $\mathrm{NHCOCH}_{3}\left(\mathrm{IC}_{50} 1.0 \mu \mathrm{M}\right)$ 12bb R = CN $\left(\mathrm{IC}_{50} 1.1 \mu \mathrm{M}\right)$

Figure 5. Derivatives of pyridine and pyrimidine.

Among these derivatives, compound 12a demonstrated the best curative effect, which was better than that of commercial agent Ningnanmycin. ${ }^{32}$

Liu et al. designed and synthesized a series of novel thiopheno[3,2- $d]$ pyrimidine derivatives with variety of substituents on cyclohexyl moiety that possibly interact with binding pocket of HIV-1 non-nucleoside reverse transcriptase and evaluated their activity against HIV-1 strains. All the derivatives exhibited moderate to excellent potency against wild-type HIV-1 in MT-4 cells. Among them, compounds 12ba,bb were effective against most tested mutant strains in MT-4 cells and proved to be active at nanomolar concentration $\left(\mathrm{EC}_{50} 9.2\right.$ and $7.1 \mathrm{nM}$, respectively). Notably, both of compounds showed potent antiviral activity against K103N and E138K strains (Fig. 5). ${ }^{33}$

\section{Quinazoline, quinoxaline}

Quinazoline and its isomer quinoxaline are bicyclic aromatic heterocycles consisting of two fused cycles benzene and pyrimidine. A representative series of 4-aminotetrahydroquinazoline derivatives $\mathbf{1 3}$ with aliphatic and aromatic substituents as well as with adamantyl framework (Fig. 6) were investigated in relation of their activity against TBEV reproduction in porcine embryo kidney

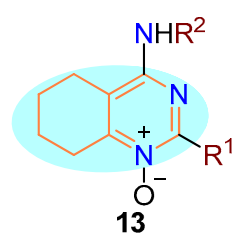

$\mathrm{R}^{1}=\mathrm{Me}, \mathrm{Et}, t-\mathrm{Bu}$

$\mathrm{R}^{2}=\mathrm{CH}_{2}(1-\mathrm{Ad}), \mathrm{CH}(1-\mathrm{Ad}) \mathrm{Me}$

$\left(\mathrm{CH}_{2}\right)_{2}(1-\mathrm{Ad}),\left(\mathrm{CH}_{2}\right)_{2}(2-\mathrm{Ad})$,

$\left(\mathrm{CH}_{2}\right)_{2} \mathrm{O}(1-\mathrm{Ad}), \mathrm{CH}(1-\mathrm{Ad}) \mathrm{Ph}$,<smiles></smiles>

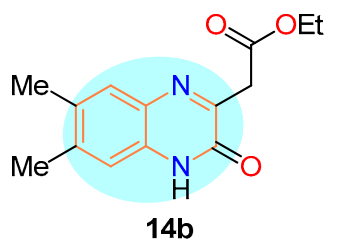

14aa $X=\mathrm{CH}, \mathrm{R}^{1}=\mathrm{COOEt}$

14ab $X=\mathrm{CH}, \mathrm{R}^{1}=\mathrm{COOH}$

14ac $X=N, R^{1}=$ COOEt
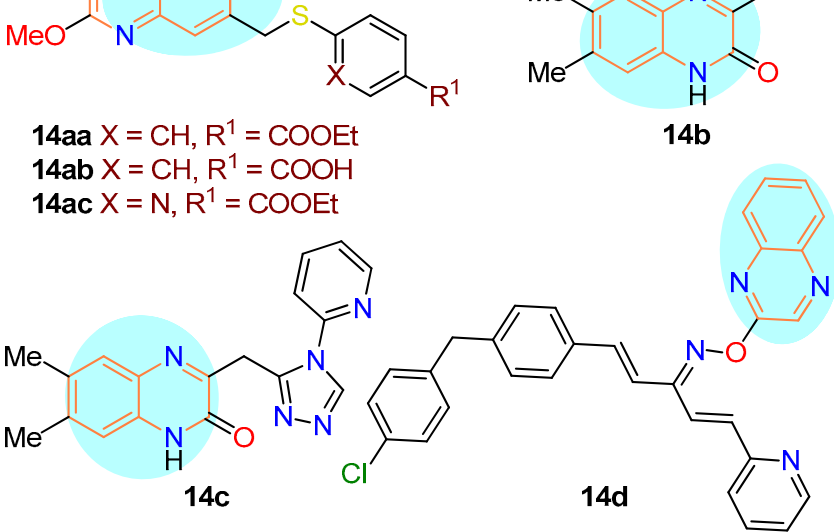

Figure 6. Derivatives of quinazoline and quinoxaline.

(PEK) cells. A bulky hydrophobic adamantane fragment was identified to be important for the antiviral activity. ${ }^{34}$

Quinoxaline derivatives are an emergent class of heterocyclic compounds with a wide spectrum of biological activities and therapeutic applications. The synthesis of some quinoxaline derivatives and evaluation of their cytotoxic and antiviral activity against different RNA and DNA viruses is a hot research topic. Enteroviruses CV-B4 and CV-B5 infections have a worldwide distribution and cause many harmful diseases. CV-B5 is associated with encephalitis and myocarditis in immunocompromised children and central nervous system disease in the elderly adults. Three compounds 14aa-ac showed very potent and selective antiviral activity against CV-B5 and cytotoxicity against different cell lines (MT-4, MDBK, BHK, and Vero-76). In addition compound 14aa inhibits the penetration possibly targeting the viral capsid protein VP1. ${ }^{35}$

Different quinoxalin-2-one derivatives were synthesized via different nucleophilic reactions. Synthesized compounds were tested for antiviral activity against $\mathrm{HCV}$, $\mathrm{HBV}$, and HSV-1. Simultaneously their safety profile as well as selectivity against viral strains were investigated. Thus, two of the test compounds, namely, quinoxalin2-ones $\mathbf{1 4 b}, \mathbf{c}$ showed potent activity and selectivity against $\mathrm{HCV}$ compared to that of ganciclovir as well as exhibited low cytotoxicity index against cell viability. ${ }^{36}$

A series of penta-1,4-dien-3-one oxime ethers containing quinoxaline moiety were synthesized and their antiviral activity was evaluated against TMV. Compound 14d showed remarkable curative, protective, and inactivation activity against TMV. The antiviral activity of this compound was evaluated by the half-leaf method using the commercial agent Ningnanmycin in the control experiment. $^{37}$ 
This review points out a growing interest in the development of heterocyclic compounds and their applications in antiviral treatment. Highly potent and specific antiviral drugs are now available for treatment of different types of viruses. The emergence of viral resistance demands new chemical scaffolds in selective treatment. Many scientific groups turn their attention to heterocyclecontaining theraupeutic agents that may emerge effective against virus strains. Future research will be focused on the chemical functionalization of some heterocyclic moieties to improve their inhibitory activity and make them a great antiviral platform giving a direct impact on the environment and society.

This review article was prepared with financial support from the CSIR-Major Research Project (Ref. No. 02(0383)/19/EMR-II). We are grateful to the Department of Chemistry, Visva-Bharati and DST-FIST and UGC-SAP program.

\section{References}

1. Eg, S.; Lakshmanan, B. Asian J. Pharm. Clin. Res. 2020, 13, 30.

2. Furuyama, W.; Marzi, A. Annu. Rev. Virol. 2019, 6, 435.

3. Musso, D.; Ko, A. I.; Baud, D. N. Engl. J. Med. 2019, 381, 1444.

4. (a) El-Sebaey, S. A. ChemistrySelect 2020, 5, 11654. (b) Wang, M.; Cao, R.; Zhang, L.; Yang, X.; Liu, J.; Xu, M.; Shi, Z.; Hu, Z.; Zhong, W.; Xiao, G. Cell Res. 2020, 30, 269.

5. Gilbert, C.; Bestman-Smith, J.; Boivin, G. Drug Resist. Updates 2002, 5, 88.

6. Ormrod, D.; Scott, L. J.; Perry, C. M. Drugs 2000, 59, 839.

7. Eftekhari-Sis, B.; Zirak, M.; Akbari, A. Chem. Rev. 2013, 113, 2958.

8. Kerru, N.; Maddila, S.; Jonnalagadda, S. B. Curr. Org. Chem. 2019, 23, 3154.

9. Ju, Y.; Varma, R. S. J. Org. Chem. 2006, 71, 135.

10. Zárate-Zárate, D.; Aguilar, R.; Hernández-Benitez, R. I.; Labarrios, E. M.; Delgado, F.; Tamariz, J. Tetrahedron 2015, $71,6961$.

11. Sravanthi, T. V.; Manju, S. L. Eur. J. Pharm. Sci. 2016, 91, 1.

12. Abdel-Gawad, H.; Mohamed, H. A.; Dawood, K. M.; Badria, F. A.-R. Chem. Pharm. Bull. 2010, 58, 1529.

13. Zoidis, G.; Giannakopoulou, E.; Stevaert, A.; Frakolaki, E.; Myrianthopoulos, V.; Fytas, G.; Mavromara, P.; Mikros, E.; Bartenschlager, R.; Vassilaki, N.; Naesens, L. MedChemComm 2016, 7, 447.

14. Bond, S.; Draffan, A. G.; Fenner, J. E.; Lambert, J.; Lim, C. Y.; Lin, B.; Luttick, A.; Mitchell, J. P.; Morton, C. J.; Nearn, R. H.; Sanford, V.; Anderson, K. H.; Mayes, P. A.; Tucker, S. P. Bioorg. Med. Chem. Lett. 2015, 25, 976.

15. Bernardino, A. M. R.; Azevedo, A. R.; Pinheiro, L. C. S.; Borges, J. C.; Paixão, I. C. P.; Mesquita, M.; Souza, T. M. L.; dos Santos, M. S. Org. Med. Chem. Lett. 2012, 2, 1.

16. Han, C.; Guo, Y.-C.; Wang, D.-D.; Dai, X.-J.; Wu, F.-J.; Liu, H.-F.; Dai, G.-F.; Tao, J.-C. Chin. Chem. Lett. 2015, 26, 534.

17. Luo, Y.; Yao, J.-P.; Yang, L.; Feng, C.-L.; Tang, W.; Wang, G.-F.; Zuo, J.-P.; Lu, W. Arch. Pharm. (Weinheim, Ger.) 2011, 344, 78.
18. Shaker, Y. M.; Omar, M. A.; Mahmoud, K.; Elhallouty, S. M.; El-Senousy, W. M.; Ali, M. M.; Mahmoud, A. E.; AbdelHalim, A. H.; Soliman, S. M.; El Diwani, H. I. J. Enzyme Inhib. Med. Chem. 2015, 30, 826

19. Enguehard-Gueiffer, C.; Musiu, S.; Henry, N.; Véron, J.-B.; Mavel, S.; Neyts, J.; Leyssen, P.; Paeshuyse, J.; Gueiffier, A. Eur. J. Med. Chem. 2013, 64, 448.

20. Bassyouni, F.; Gaffer, A. E. D.; Roaiah, H.; El-Senousy, W. M.; Nakkady, S. S. E.; Rehim, M. A. Res. J. Pharm., Biol. Chem. Sci. 2016, 7(6), 24.

21. Barradas, S. J.; Errea, I. M.; D'Accorso, N. B.; Sepúlveda, C. S.; Damonte, E. B. Eur. J. Med. Chem. 2011, 46, 259.

22. Dawood, K. M.; Eldebss, T. M. A.; El-Zahabi, H. S. A.; Yousef, M. H. Eur. J. Med. Chem. 2015, 102, 266.

23. Lozynskyi, A.; Golota, S.; Zimenkovsky, B.; Atamanyuk, D.; Gzella, A.; Lesyk, R. Phosphorus, Sulfur Silicon Relat. Elem. 2016, 191, 1245.

24. Hu, J.; Ma, L.; Wang, H.; Yan, H.; Zhang, D.; Li, Z.; Jiang, J.; Li, Y. Virol. J. 2017, 14, 55.

25. McDowell, M.; Gonzales, S. R.; Kumarapperuma, S. C.; Jeselnik, M.; Arterburn, J. B.; Hanley, K. A. Antiviral Res. 2010, 87, 78 .

26. Zhao, X.; Liao, A.; Zhang, F.; Zhao, Q.; Zhou, L.; Fan, J.; Zhang, Z.; Wang, Z.; Wang, Q. J. Heterocycl. Chem. 2019, 57, 761.

27. Albratty, M.; El-Sharkawy, K. A.; Alhazmi, H. A. Acta Pharm. 2019, 69, 261.

28. Xu, W.-M.; Li, S.-Z.; He, M.; Yang, S.; Li, X.-Y.; Li, P. Bioorg. Med. Chem. Lett. 2013, 23, 5821.

29. de Castro, S.; Familiar, O.; Andrei, G.; Snoeck, R.; Balzarini, J.; Camarasa, M.-J.; Velázquez, S. ChemMedChem 2011, 6, 686.

30. Abu-Zaied, M. A.; Hammad, S. F.; Halaweish, F. T.; Elgemeie, G. H. ACS Omega 2020, 5, 14645.

31. Li, T.; Zhang, J.; Pan, J.; Wu, Z.; Hu, D.; Song, B. Eur. J. Med. Chem. 2017, 125, 657.

32. Wu, W.-N.; Tai, A.-Q.; Chen, Q.; Ouyang, G.-P. J. Heterocycl. Chem. 2016, 53, 626.

33. Kang, D.; Ding, X.; Wu, G.; Huo, Z.; Zhou, Z.; Zhao, T.; Feng, D.; Wang, Z.; Tian, Y.; Daelemans, D.; De Clercq, E.; Pannecouque, C.; Zhan, P.; Liu, X. ACS Med. Chem. Lett. 2017, 8, 1188.

34. Sedenkova, K. N.; Dueva, E. V; Averina, E. B.; Grishin, Y. K.; Osolodkin, D. I.; Kozlovskaya, L. I.; Palyulin, V. A.; Savelyev, E. N.; Orlinson, B. S.; Novakov, I. A.; Butov, G. M.; Kuznetsova, T. S.; Karganova, G. G.; Zefirov, N. S. Org. Biomol. Chem. 2015, 13, 3406.

35. Carta, A.; Sanna, G.; Briguglio, I.; Madeddu, S.; Vitale, G.; Piras, S.; Corona, P.; Peana, A. T.; Laurini, E.; Fermeglia, M.; Pricl, S.; Serra, A.; Carta, E.; Loddo, R.; Giliberti, G. Eur. J. Med. Chem. 2018, 145, 559.

36. El-Zahabi, H. S. A. Arch. Pharm. (Weinheim, Ger.) 2017, 350, e1700028.

37. Xia, R.; Guo, T.; Chen, M.; Su, S.; He, J.; Tang, X.; Jiang, S.; Xue, W. New J. Chem. 2019, 43, 16461.

38. Hantzsch, A.; Weber, J. H. Eur. J. Inorg. Chem. 1887, 20, 3118.

39. Fan, Z..; Yang, Z.; Zhang, H.; Mi, N.; Wang, H.; Cai, F.; Zuo, X.; Zheng, Q.; Song, H. J. Agric. Food Chem. 2010, 58, 2630.

40. Wang, Z.-H.; Guo, Y.-Z.; Zhang, J.; Ma, L.; Song, H.-B.; Fang, Z.-J. J. Agric. Food Chem. 2010, 58, 2715. 